\title{
Operative Steps for OS-ASD Closure for Beginners
}

\author{
Amitabh Satsangi ${ }^{1}$, Biswajit Singh ${ }^{2}$, Surabhi Puri ${ }^{3}$ \\ ${ }^{1}$ Department of Cardiothoracic and Vascular Surgery, All India Institute of Medical Sciences, New Delhi, India \\ ${ }^{2}$ Department of Surgical Disciplines, All India Institute of Medical Sciences, New Delhi, India \\ ${ }^{3}$ Department of Community Medicine, All India Institute of Medical Sciences, New Delhi, India
}

\section{Email address:}

amoeba418@gmail.com (A. Satsangi)

\section{To cite this article:}

Amitabh Satsangi, Biswajit Singh, Surabhi Puri. Operative Steps for OS-ASD Closure for Beginners. International Journal of Cardiovascular and Thoracic Surgery. Vol. 6, No. 2, 2020, pp. 23-27. doi: 10.11648/j.ijcts.20200602.12

Received: May 27, 2020; Accepted: June 12, 2020; Published: June 29, 2020

\begin{abstract}
In the current era of cardiothoracic surgery, a trainiee embarks on his operative journery with learing to operate upon a patient suffering from ostium secundum atrial septal defect. This procedure involves all the essential steps required in cardiac surgery procedures and one should master the steps of this operation to be able to perform and understand other cardiac operations. OS-ASD closure is one of the first open heart procedures performed by a trainee or resident. This article deals with detailed operative steps as to how to perform sternotomy, put a patient on cardiopulmonary bypass machine, perform atrial septum defect closure and get a patient off cardiopulmonary bypass. Procedural training in current practice is often unsystematic and unstructured, and validated teaching methods have not been well integrated into clinical education. Minutest details performed during the procedure are mentioned in this article aimed for residents in cardiovascular thoracic surgery. Though there are multiple texts available in literature as how to perform the above mentioned procedure, they lack in technical details and thus residents have difficulty while operating. I would like to delineate detailed steps for ostium secundum atrial septum closure for beginners. This is meant for revision preoperatively of all the step one has to perform while doing surgery.
\end{abstract}

Keywords: Operative Steps, OS-ASD Surgical Closure, Technical Notes

\section{Introduction}

Open heart surgeries are one of the most technically challenging surgeries.

Procedural training in current practice is often unsystematic and unstructured, and validated teaching methods have not been well integrated into clinical education. [1]

The first successful closure of an ASD was performed by F. John Lewis in 1952 with inflow occlusion under hypothermia. [2]

Today ASDs are closed using cardiopulmonary bypass (CPB) with direct vision of the lesion. The classic approach is by median sternotomy, however, other approaches are used as well in an effort to reduce morbidity. [3]

Cardiopulmonary bypass serves the purpose of acting in place of the patient's heart and lungs during a cardiac operative procedure. [4]

Residents usually begin their operative journey in cardiac surgery by learning to put a patient on cardio-pulmonary bypass machine and basic surgery like ostium secundum atrial septal defect.

Operation generally begins with a median sternotomy which is a gold standard approach to access the heart. [5]

Median sternotomy was first proposed by Milton in 1897. [6]

Through this approach, the surgeon can see the entire heart and control the whole operative field visually and tactically.

Post a successful sternotomy, its time for aortic cannulation, which requires a meticulous approach.

The technique of aortic cannulation varies from center to center. Some surgeons place a partial occluding clamp on the aorta, make an incision in the aorta, and then put a pursestring suture around the cannula. [7] Other surgeons place a pursestring in the adventitia, make a small opening in the aorta, dilate the opening, and then introduce the aortic cannula. [8]

The latter approach is universally accepted now a days.

Reproducible, simple aortic cannulation is an essential 
feature of safe cardiac operations. Bleeding should be minimal, and the problem of forward or retrograde dissection should not occur. [9]

Post aortic cannulation, serial venous cannulation is performed in order to create venous drainage.

The purpose of venous cannulation is to drain systemic deoxygenated blood into a cardiopulmonary bypass machine. Central venous cannulation for cardiopulmonary bypass is usually accomplished by cannulation of the right atrial appendage, the lateral wall of the right atrium, the superior vena cava, or the inferior vena cava. [10-12]

After venous cannulation, the patient is ready to be put on cardiopulmonary bypass.

Cardiopulmonary bypass is initiated serially, first the patient is put on partial cardiopulmonary bypass and then complete cardiopulmonary bypass is initiated. [13]

After the initiation of cardiopulmonary bypass one gets ready to arrest the heart, keeping in mind the concept of myocardial protection, which is of uttermost importance.

Myocardial protection during cardiac surgery aims to preserve myocardial function while providing a bloodless and motionless operating field to make surgery easier. [14]

This is achieved by cardioplegia induced diastolic arrest, surface cooling of heart, venting of heart and proper drainage of heart via the venous cannulae. [15]

Once arrested and adequate myocardial protection is achieved, then begins the open heart surgery.

It is important to be thorough with the operative steps as to how to put the patient on cardio-pulmonary bypass and come off cardiopulmonary bypass safely.

Though there are multiple texts available in literature as how to perform the above mentioned procedure, they lack in technical details and thus residents have difficulty while operating.

I would like to delineate detailed steps for ostium secundum atrial septum closure for beginners.

\section{Operative Steps}

The patient lies in a supine position with the arms secured at his side.

Antibiotic prophylaxis is given intravenously within $1 \mathrm{~h}$ of the incision and the patient is draped according to the institutional protocol with a transparent film covering the skin.

Median skin incision marked using a silk thread- incision has to be median and vertical between the sternal notch and the tip of the xiphoid process.-skin incision using 23 no blade-cautery (coagulation 40 effect-4) used to separate subcutaneous tissue-xiphoid process identified-creation of space at the end of xiphoid process at the midpoint of ant. Rectus sheath-exposure of supra-clavicular notch space using Czerny retractor (pole)-clipping and diving of any engorged veins-stripping off of fascia-identification of inter-jugular or inter-clavicular ligament-freeing from surrounding fascia-with help of right angle, the posterior structures are pushed back-division of inter-clavicular ligament-midline is marked on the sternum-check pneumatic saw-ask anaesthetist for lungs down-check etco 2 curve -check flat line of etco2-engage saw-keep saw slowly over midline (use both hands on the saw)-at the end of sternotomy, lungs back up-put sponge inside the chest cavity-check for the active bleeding points -cauterize them first (using ball cautery)-attain haemostasis first on the outer table, then on inner table-take out sponge-take chest/sternum retractor and open the retractor-check for pleura if open-with cautery (cutting tip on 20) horizontally splay thymus, identify the plane between the two lobes and dissect between the plane very carefully until the innominate vein can be identified-identify the pericardium over the aorta just at the root of the aorta-use pick up to catch the pericardium and ask first assistant to hold pericardium parallel to where you are holding-lift up the pericardium, use the cautery to open the pericardium-open up superiorly up till the end of ascending aorta-inferiorly go up to $1 \mathrm{~cm}$ above the diaphragm-then cut the pericardium parallel to the diaphragm-take pericardial stays 2'0 silk-first two stays at the pericardium adjacent to the ascending aorta for aortic cannulation-next stay for svc exposure-next for right atrium exposure-next for inferior vena cava exposureone stay at the opposite side-tell the second assistant to circulate and divide the lines-take aortic purse string using 3-0 t3 (17mm) ethibond (adult patients, thin aorta 4-0 sh prolene used)-start from 2'o clock (bite should be superficial taking adventitia and very minimal on the media)-first bite is forehand, $2^{\text {nd }}$ bite forehand, $3^{\text {rd }}$ bite backhand, $4^{\text {th }}$ fore hand-after the first purse string equalise both the ends and then proceed-after completion of first purse string hold sutures taut in the air for first assistant to cut and hand back the needles to nursing officer- $2^{\text {nd }}$ assistant will snug, apply snap at the distal end of the snugger and the extra suture is put in the rachet of the snapheparinise the patient $(4 \mathrm{mg} / 400 \mathrm{iu} / \mathrm{kg})$ start second purse string from 12 'o clock position-repeat same process as the first purse string-at the end of two aortic purse strings- ask if 3 mins to heparin-get ready for aortic cannulation (aortic cannulation can be done as the first cannulation also and routinely it is done as the first cannulation)-using a right angle, hold the fat pad of aorta to stabilise the aorta- ask the first assistant to stabilise the aorta-using pick up grab the adventitia using Metzenbaum scissors cut the tissue to bare the media, cut inside the purse string, bare media adequately-lower the pressures to $100 / 60 \mathrm{mmhg}$ for cannulation-grab the adventitia with pick up and mobilize the tissue to cover the bared media-tell the first assistant to hold the aortic cannula-using 11 no blade, stab aorta and cut towards the first assistant-try aortic cannulation under vision, once cannulated, tell the assistant to hold the cannula-snug both the snuggers - tie one snugger to the aortic cannula-use thumb to occlude the aortic cannula orifice and open the tube clamp and deair the aortic cannula-reapply the clamp on the aortic cannula-bring the bowl and arterial line close to the cannula-holding the aortic cannula and the arterial line as vertical and close to each 
other, tell perfusionist to "push"-connecting the aortic cannula and the arterial line without any air bubble is important-when connected tell to stop "pushing"-ensure there is no air bubble then open the aortic clamp-ask the perfusionist to check line pressures and oscillations-fix the aortic cannula to the skin at the apex of skin incision-use towel clips to fix the aortic cannula-take becks clamp. Tell the first assistant to hold the right atrium appendage, apply becks clamp-use pick up to provide counter traction, use Metzenbaum scissors to cut the right atrial appendage, cut internal trabeculations to make space for ra cannula-take purse string (4'0 prolene), start from the lower border of the proposed cannulation site and move upwards, using same needle come back down to complete the purse string-snug the purse string after cutting the needles (snug loosely)-get ready with the svc/right atrial appendage cannula-release the becks clamp, use forceps to hold the right atrial appendage and guide the cannula inside the right atrial appendage in a rotating manner-snug the cannula (let the first assistant snug the cannula while you hold it in position)-tie the cannula and the snugger together-connect it to the appropriate venous line (don't remove clamps)- take 4'0 prolene, tell $1^{\text {st }}$ assistant to retract for exposure for Inferior vena cava purse-string-taking the needle in back hand take the lower end of purse string first, near the inferior vena cava - right atrium junction-leave the needle holder along with the needle of the lower end of the purse string near the head end-take the other end of purse string needle take upper part of the purse-string, hold both the needle, let first assistant cut the needle, needle back to the nursing officer, snug the purse-string (loose)-take 11 no blade, stab inferior vena cava, take Metzenbaum scissors with the curved end facing upwards (towards you) dilate the stabbed inferior vena cava -tell to increase the suction of pump suckers-introduce the inferior vena cava cannula inside up till 5 mark on the cannula (for adults), tell the first assistant to snug the cannula, tie the snugger and the cannula-check the act (above 400) go on bypass, tell the perfusionist to go on partial bypass then complete bypass (serially releasing inferior vena cava and svc cannula clamps)-using Metzenbaum scissors between inferior vena cava-right atrium junction inferiorly and lower pulmonary vein dissect for the space (with Metzenbaum scissors opening horizontally) to loop for inferior vena cava, dissection stops when the blood gushes into the area where you are dissecting-try opening and closing the instrument with little force to tease off the tissue-once the space is created and the instrument is passed, use umbilical tape to loop inferior vena cava and loosely snug it, apply the curved snap on the umbilical tape-using cautery create the space between right pulmonary artery and superior vena cava, using right angle, loop the sve in similar manner with pushing right pulmonary artery posteriorly, once looped don't snug the svc-cut the tie between the snugger and the right atrial cannula, mobilize the cannula, direct the cannula into the superior vena cava, once in superior vena cava, tie the cannula and the snugger-now snug the looped svc and tightened the loop, ask for the return from the perfusionistusing the cautery bare the aorta for cardioplegia purse string, take 3'0 t3 two horizontal bites towards yourself and two horizontal bites away from yourself, put a pick up into the loop towards yourself, cut the needles and snug the suture loose-take cardioplegia cannula, engage in the loop on your side, direct it towards the aorta with first assistant pulling the opposite suture, once the aorta is pierced, snug the purses ring (done by first assistant)-take out the stylet, direct the cannula down into the pericardium to avoid blood spurting, apply 3 way, and tie cardioplegia cannula and the snugger-connect the cardioplegia line, flush cardioplegia until blood appears, stop flushing-use adenosine attach to 3 way -get ready for clamping the aorta, ask perfusionist to decrease the flows by saying "flows down", clamp the aorta and say back up- tell $1^{\text {st }}$ assistant to give adenosine and then cardioplegia (del nido - 30ml/kg, St. Thomas-20 ml $/ \mathrm{kg}$ )start pouring cold saline over the rt ventricle and pericardial cavity-use heavy sucker for suctioning-once cardioplegia given, inferior vena cava snugged and asked to check return-hold the right atrial appendage with pickup $1.5 \mathrm{~cm}$ away from atrio-ventricular groove, take 11 no blade, tell the perfusionist to watch for air, stab the right atrial, using potts scissors cut the right atrial wall directly behind the inferior vena cava cannula and superiorly up till the right atrial appendage tip-visualize atrial septal defect, check any unusual papvc's -use right atrial stays at the crista total 4 stays, 2 towards $1^{\text {st }}$ assistant, two towards yourself, apply rubber shot to each-take dacron patch, size it according to the defect (in a large right atrium, right atrial free wall patch can be used)-take 5'0 prolene double arm-pass first suture through the patch and leave it at the head end-using the second needle take a bite at the margin of ostium secundum atrial septal defect -keep moving towards yourself, lower the patch onto the defect, keep on suturing up till upper edge of the ostium secundum atrial septum defect, now take the other end, first on ostium secundum atrial septum defect border then on the patch-at the end when about to seal the ostium secundum atrial septum defect, ask the anaesthetist to ventilate and de-air the left atrium -once the left atrium has been deaired, take finishing the bite and the two sutures and cut-start for ra closure using 5'0 prolene, take a bite at the lower apex of right atrial incision, tie knot between the two arms of the sutureapply rubber shot on one end and start suturing right atrium -after reaching the upper apex, de-air right atrium, by asking the perfusionist to fill the heart or by clamping the inferior vena cava cannula temporarily, de-snug the loop of inferior vena cava cannula-once de-aired complete right atrial closure (one-layer)-root vent kept ready-get ready to de-air the heart, head end is elevated ask perfusionist to fill the heart, tell anaesthetist to do manual hand bag ventilation-manually with the thumb, milk the pulmonary veins index finger to left atrial appendage, middle and ring on the right ventricle compress and get air out of the ventricles for some time, after few minutes of de-airing, watch the air bubbles come out of the cardioplegia cannula, 
pinch the root the aorta and get ready for declamping the aorta, the head end is lowered, flows are turned down, the root of aorta is still pinched, clamp is off, flows back up, partial head up, and the root vent is connected to the cardioplegia cannula and turned on, the aortic root is still pinched unless the head end is completely back to normalnow the second layer of right atrium is completed, both the sutures are tied, meanwhile svc is desnugged and the svc cannula is pulled back into right atrium-pacing wires are applied -2 atrial and 1 ventricle-inferior vena cava cannula is clamped, patient on partial bypass, inferior vena cava cannula is decannulated, inferior vena cava re-enforcement taken, placement of drain done (mediastinal/intercostal)after 5 mins of root vent time is done-ensure suture line once-svc cannula is clamped after coming off bypass ensuring adequate haemoglobin, $\mathrm{k}+$ levels, pressures, normal sinus rhythm, ph., contractility- right atrium is decannulated, protamine started, when $50 \%$ protamine given right atrial appendage purse string is tied and after cardioplegia cannula/root vent is removed and reinforcement taken-plan for aortic decannulation-cut the tie between the snugger and the cannula, get ready to tie yourself, first assistant will snug and take out the cannulaonce cannula is out, tie your end, then once secured, tell assistant to tie their side-aortic reinforcement is done (4'0 sh prolene)-check for bleeding site/suture line-give warm saline wash-close the pericardium, pacing wire fixation is done, drain fixation is done place the sponge in the cavitysternal closure with 5 no. ethibond (all bites forehand)-use at least 4 ethibond sutures -all are taken in crisscross manner-after taking sternal bites, check for bleeding points and achieve haemostasis-remove the sponge -ask scrub nurse if counts are clear -sternal suture tying-cutting the excessive knots -subcutaneous (2-0 vicryl) and skin closure (3-0 prolene), use suction to drain the drains.

Aseptic dressing is applied and patient is shifted to intensive care unit.

\section{Conclusion}

These steps might differ in view of surgeon to surgeon variation.

Residents while performing open heart surgery should be thorough with the basic steps and this article is written with the intent to focus detailed steps which one requires to perform an os-asd closure operation.

\section{Funding}

No funding source.

\section{Conflict of Interest}

All the authors do not have any possible conflicts of interest.

\section{Ethical Approval}

Not applicable.

\section{Human Rights}

Not applicable.

\section{References}

[1] Grantcharov T. P., Reznick R. K. Teaching procedural skills, $B M J, 2008$, vol. 336 (pg. 1129-1131).

[2] Alexi-Meskishvili VV, Konstatinov IE. Surgery for atrial septal defect: from first experiments to clinical practice. Ann Thorac Surg. 2003; 76: 322-7.

[3] Liava'a, Matthew, and David Kalfa. "Surgical closure of atrial septal defects." Journal of thoracic disease vol. 10, Suppl $24 \quad$ (2018): $\quad$ S2931-S2939. doi: 10.21037/jtd.2018.07.116.

[4] Emily Bond, Crystal Valadon and Mark Slaughter (October 3rd 2019). Cannulation for Cardiopulmonary Bypass, Cardiac Surgery Procedures, Andrea Montalto, Antonio Loforte and Cristiano Amarelli, IntechOpen, DOI: 10.5772/intechopen.86033. Available from: https://www.intechopen.com/books/cardiac-surgeryprocedures/cannulation-for-cardiopulmonary-bypass.

[5] Reser, D., Caliskan, E., Tolboom, H., Guidotti, A., \& Maisano, F. (2015). Median sternotomy. Multimedia Manual of Cardio-Thoracic Surgery, 2015, mmv017. doi: 10.1093/mmcts/mmv017.

[6] Julian OC, Lopez-Belio M, Dye WS, Javid H, Grove WJ. The median sternal incision in intracardiac surgery with extracorporeal circulation: a general evaluation of its use in heart surgery. Surgery $1957 ; 42$ : 753-61.

[7] Cooley DA, Norman JC: Cannulation for temporary bypass. In Techniques in Cardiac Surgery. Houston, Texas Medical Press, 1975, p 57.

[8] Roe BB, Kelly PB: Perfusion through the ascending aorta: experience with 410 cases. Ann Thorac Surg 7: 238, 1969.

[9] Garcia-Rinaldi R, Vaughan III GD, Revuelta JM, Goiti JJ, Gomez-Duran C. Simplified aortic cannulation. The Annals of thoracic surgery. 1983 Aug 1; 36 (2): 226-7.

[10] Hessel EA II, Edmunds LH Jr. Perfusion systems. In: Cohn LH, Edmunds LH Jr, eds. Cardiac surgery in the adult. 2nd ed. New York, NY: McGrawHill, 2003; 317-338.

[11] Hessel EA. Cardiopulmonary bypass equipment. In: Estafanous FG, Barash PG, Reves JG, eds. Cardiac anesthesia: principles and clinical practice. 2nd ed. Philadelphia, Pa: Lippincott Williams \& Wilkins, 2001; 335-386.

[12] Khonsri S, Sintek CF. Cardiac surgery: safeguards and pitfalls in operative techniques. 4th ed. Philadelphia, Pa: Lippincott Williams \& Wilkins, 2008; 21-46.

[13] Sarkar, Manjula, and Vishal Prabhu. "Basics of cardiopulmonary bypass." Indian journal of anaesthesia vol. 61, 9 (2017): 760-767. doi: 10.4103/ija.IJA_379_17. 
[14] Francesco Nicolini, Cesare Beghi, Claudio Muscari, Andrea Agostinelli, Alessandro Maria Budillon, Igino Spaggiari, Tiziano Gherli, Myocardial protection in adult cardiac surgery: current options and future challenges, European Journal of Cardio-Thoracic Surgery, Volume 24, Issue 6, December 2003, Pages 986-993, https://doi.org/10.1016/S1010-7940(03)00475-5.
[15] Talwar, S., Jha, A. J., Hasija, S. et al. Paediatric myocardial protection-strategies, controversies and recent developments. Indian J Thorac Cardiovasc Surg 29, 114-123 (2013). https://doi.org/10.1007/s12055-013-0208-2. 